\title{
A hybrid inertial algorithm for approximating solution of convex feasibility problems with applications
}

\author{
Charles E. Chidume ${ }^{1}$, Poom Kumam ${ }^{2 *}$ and Abubakar Adamu
}

\author{
"Correspondence: \\ poom.kumam@mail.kmutt.ac.th \\ ${ }^{2}$ Center of Excellence in Theoretical \\ and Computational Science \\ (TaCS-CoE), Science Laboratory \\ Building, King Mongkuts University \\ of Technology Thonburi (KMUTT) \\ Bangkok, Thailand \\ Full list of author information is \\ available at the end of the article
}

\begin{abstract}
An inertial iterative algorithm for approximating a point in the set of zeros of a maximal monotone operator which is also a common fixed point of a countable family of relatively nonexpansive operators is studied. Strong convergence theorem is proved in a uniformly convex and uniformly smooth real Banach space. This theorem extends, generalizes and complements several recent important results. Furthermore, the theorem is applied to convex optimization problems and to J-fixed point problems. Finally, some numerical examples are presented to show the effect of the inertial term in the convergence of the sequence of the algorithm.
\end{abstract}

Keywords: Inertial; Maximal monotone; Fixed point; Hybrid

\section{Introduction}

An inertial-type algorithm was first introduced and studied by Polyak [35], as a method of speeding up the convergence of the sequence of an algorithm. This algorithm is a two step iterative procedure in which the successive iterates are obtained by using two previous iterates. Numerical experiments have shown that an algorithm with an inertial extrapolation term converges faster than an algorithm without it. Thus, one can see an increasing interest in the class of inertial-type algorithms (see, for example, the following papers $[12,26,44]$ and the references therein).

Let $X$ be a real normed space with dual space $X^{*}$. Let $T: X \rightarrow 2^{X^{*}}$, be a set-valued operator with domain $D(T):=\{p \in X: T p \neq \emptyset\}$, range $R(T):=\bigcup_{p \in D(T)}\{T p\}$ and graph $G(T):=\left\{\left(p, p^{*}\right): p^{*} \in T p\right\}$. Then $T$ is called monotone if

$$
\left\langle p-q, p^{*}-q^{*}\right\rangle \geq 0, \quad \forall p^{*} \in T p, q^{*} \in T q .
$$

$T$ is said to be maximal monotone if $G(T)$ is not properly contained in the graph of any other monotone operator. Monotone maps were first introduced by Minty [29] to aid in the abstract study of electrical networks and later studied by Browder [4] in the setting of partial differential equations. Later, Kačurovskii [19], Minty [30], Zarantonello [48] and many other authors studied this class of operators in Hilbert spaces. Interest in monotone

(c) The Author(s) 2020. This article is licensed under a Creative Commons Attribution 4.0 International License, which permits use, sharing, adaptation, distribution and reproduction in any medium or format, as long as you give appropriate credit to the original author(s) and the source, provide a link to the Creative Commons licence, and indicate if changes were made. The images or other third party material in this article are included in the article's Creative Commons licence, unless indicated otherwise in a credit line to the material. If material is not included in the article's Creative Commons licence and your intended use is not permitted by statutory regulation or exceeds the permitted use, you will need to obtain permission directly from the copyright holder. To view a copy of this licence, visit http://creativecommons.org/licenses/by/4.0/ 
operators stems mainly from their various applications (see e.g., the following monographs $[2,5,17]$ and the references therein).

A fundamental problem of interest in the study of monotone operators in Banach spaces is the following:

Find $p \in X$ such that $0 \in T p$.

For the prove of existence of solutions of (1.2) see, for example, Browder [3], and Martin [27]. Many problems in applications can be transformed into the form of the inclusion (1.2). For example, problems arising from convex minimization, variational inequality, Hammerstein equations, and evolution equations can be transformed into the form of the inclusion (1.2) (see, e.g., Chidume et al. [8, 14], Rockafellar [37]).

Iterative methods for approximating solutions of the inclusion (1.2) have been studied extensively by various authors in Hilbert spaces and in more general Banach spaces. One of the classical methods for approximating solution(s) of (1.2) in Hilbert spaces is the celebrated proximal point algorithm (PPA) introduced by Martinet [28] and studied extensively by Rockafellar [37] and a host of other authors. Concerning the iterative approximation of solution(s) of (1.2) in more general Banach space, see, e.g., [6, 11, 14, 20, 32].

Let $S: X \rightarrow X$ be a map and let $p \in X, p$ be called an asymptotic fixed point of $S$ if $X$ contains a sequence $\left\{p_{n}\right\}$ which converges weakly to $p$ and $\lim _{n \rightarrow \infty}\left\|p_{n}-S p_{n}\right\|=0$. We denote the set of asymptotic fixed points of $S$ by $\widehat{F}(S)$. The map $S$ is said to be relatively nonexpansive if $\widehat{F}(S)=F(S) \neq \emptyset$ and $\psi(p, S q) \leq \psi(p, q)$, for all $p \in F(S)$ and $q \in X$, where $F(S)=\{p \in X: S p=p\}$ and $\psi$ is the Lyapunov function (see, e.g., Alber [1]).

One of the motivations for the study of relatively nonexpansive self or nonself mappings in Banach spaces is the fact that they are an extension of nonexpansive mappings with nonempty fixed point sets in Hilbert spaces. In 2018, Chidume et al. [12] introduced and studied an inertial-type algorithm in a uniformly convex and uniformly smooth real Banach space. They proved the following theorem.

Theorem 1.1 Let $B$ be a uniformly convex and uniformly smooth real Banach space. Let $T_{i}: B \rightarrow B, i=1,2,3, \ldots$ be a countable family of relatively nonexpansive maps such that $\bigcap_{i=1}^{\infty} F\left(T_{i}\right) \neq \emptyset$. Suppose $\left\{\eta_{i}\right\} \subset(0,1)$ and $\left\{\beta_{i}\right\} \subset(0,1)$ are sequences such that $\sum_{i=1}^{\infty} \eta_{i}=1$ and $T: B \rightarrow B$ is defined by $T p=J^{-1}\left(\sum_{i=1}^{\infty} \eta_{i}\left(\beta_{i} J p+\left(1-\beta_{i}\right) J T_{i} p\right)\right)$ for each $p \in B$. Let $\left\{x_{n}\right\}$ be generated by the following algorithm:

$$
\left\{\begin{array}{l}
C_{0}=B \\
w_{n}=x_{n}+\alpha_{n}\left(x_{n}-x_{n-1}\right) \\
y_{n}=J^{-1}\left((1-\beta) J w_{n}+\beta J T w_{n}\right) \\
C_{n+1}=\left\{z \in C_{n}: \psi\left(z, y_{n}\right) \leq \psi\left(z, w_{n}\right)\right\} \\
x_{n+1}=\Pi_{C_{n+1}} x_{0}
\end{array}\right.
$$

$n \geq 0$, where $\alpha_{n} \in[0,1), \beta \in(0,1)$. Then $\left\{x_{n}\right\}$ converges strongly to $p=\Pi_{F(T)} x_{0}$.

Several iterative algorithms for approximating fixed points of self maps satisfying certain contractive conditions and zeros of monotone and monotone type operators has recently been studied extensively by various authors; see e.g., [24, 33, 34, 39-42]. In 2009, Inoue et 
al. [18] introduced and studied a hybrid algorithm in a uniformly convex and uniformly smooth Banach space. They proved the following theorem.

Theorem 1.2 Let $B$ be a uniformly convex and uniformly smooth Banach space and let $C$ be a nonempty closed and convex subset of $B$. Let $A: B \rightarrow 2^{B^{*}}$ be a maximal monotone operator satisfying $D(A) \subset C$ and let $J_{r}=(J+r A)^{-1} J$ for all $r>0$. Let $S: C \rightarrow C$ be a relatively nonexpansive mapping such that $F(S) \cap A^{-1} 0 \neq \emptyset$. Let $\left\{x_{n}\right\}$ be a sequence generated by $x_{0}=x \in C$ and

$$
\left\{\begin{array}{l}
u_{n}=J^{-1}\left(\beta_{n} J x_{n}+\left(1-\beta_{n}\right) J S J_{r_{n}} x_{n}\right), \\
C_{n}=\left\{z \in C: \psi\left(z, u_{n}\right) \leq \psi\left(z, x_{n}\right)\right\}, \\
Q_{n}=\left\{z \in C:\left\langle x_{n}-z, J x_{0}-J x_{n}\right\rangle \geq 0\right\}, \\
x_{n+1}=\Pi_{C_{n} \cap Q_{n}} x,
\end{array}\right.
$$

for all $n \in \mathbb{N} \cup\{0\}$, where $J$ is the duality mapping on $B,\left\{\beta_{n}\right\} \subset[0,1]$, and $\left\{r_{n}\right\} \subset[a, \infty)$ for some $a>0$. If $\liminf _{n \rightarrow \infty}\left(1-\beta_{n}\right)>0$, then $\left\{x_{n}\right\}$ converges strongly to $\Pi_{F(S) \cap A^{-1} 0_{0} x_{0}}$.

In 2009, Klin et al. [21] extended the results of Inoue et al. [18]. They proved the following theorem.

Theorem 1.3 Let $B$ be a uniformly convex and uniformly smooth Banach space and let $C$ be a nonempty closed and convex subset of $B$. Let $A: B \rightarrow 2^{B^{*}}$ be a maximal monotone operator satisfying $D(A) \subset C$ and let $J_{r}=(J+r A)^{-1} J$ for all $r>0$. Let $S$ and $T$ be relatively nonexpansive mappings from $C$ into itself such that $\Omega=F(S) \cap F(T) \cap A^{-1} 0 \neq \emptyset$. Let $\left\{x_{n}\right\}$ be a sequence generated by $x_{0} \in C$ and

$$
\left\{\begin{array}{l}
u_{n}=J^{-1}\left(\alpha_{n} J x_{n}+\left(1-\alpha_{n}\right) J T z_{n}\right), \\
z_{n}=J^{-1}\left(\beta_{n} J x_{n}+\left(1-\beta_{n}\right) J S J_{r_{n}} x_{n}\right), \\
C_{n}=\left\{z \in C: \psi\left(z, u_{n}\right) \leq \psi\left(z, x_{n}\right)\right\}, \\
Q_{n}=\left\{z \in C:\left\langle x_{n}-z, J x_{0}-J x_{n}\right\rangle \geq 0\right\}, \\
x_{n+1}=\Pi_{C_{n} \cap Q_{n}} x_{0},
\end{array}\right.
$$

for all $n \in \mathbb{N} \cup\{0\}$, where $J$ is the duality mapping on $B,\left\{\alpha_{n}\right\},\left\{\beta_{n}\right\} \subset[0,1]$, and $\left\{r_{n}\right\} \subset[a, \infty)$ for some $a>0$. If $\liminf _{n \rightarrow \infty}\left(1-\alpha_{n}\right)>0$ and $\liminf _{n \rightarrow \infty}\left(1-\beta_{n}\right)>0$, then $\left\{x_{n}\right\}$ converges strongly to $\Pi_{\Omega} x_{0}$.

Motivated by the results of Chidume et al. [12] and Klin et al. [21], in this paper we introduce and study an inertial iterative algorithm in a uniformly convex and uniformly smooth real Banach space and prove a strong convergence theorem for approximating a common element in the set of zeros of a maximal monotone operator and the sets of fixed points of countable family of relatively nonexpansive mappings. Furthermore, we give applications of our theorem to convex optimization and $J$-fixed point. Finally, we present numerical examples to demonstrate the effect of the inertial term on the convergence of the sequence of our algorithm. 


\section{Preliminaries}

The following definitions and lemmas will be needed in the sequel.

Definition 2.1 Let $X$ be a real normed space. The normalized duality map $J$ from $X$ to $2^{X^{*}}$ is defined by $J p:=\left\{p^{*} \in X^{*}:\left\langle p, p^{*}\right\rangle=\|p\|^{2}=\left\|p^{*}\right\|^{2}, \forall p \in X\right\}$, where $\langle\cdot, \cdot\rangle$ denotes the value of $p^{*}$ at $p$ and $X^{*}$ is the dual space of $X$. It is well known that if $X$ is smooth then $J$ is single-valued and if $X$ is uniformly smooth, then $J$ is uniformly continuous on bounded subsets of $X$.

Definition 2.2 Let $B$ be a smooth real Banach space; the Lyapunov functional $\psi: B \times B \rightarrow$ $\mathbb{R}$ is defined by

$$
\psi(p, y)=\|p\|^{2}-2\langle p, J y\rangle+\|y\|^{2} .
$$

The mapping $\psi$ was introduced by Alber [1]. Since its introduction, one can notice an increasing interest in the functional see e.g., $[7,10,38,43,45,46,49]$. Observe that, in a real Hilbert space $H$, Eq. (2.1) reduces to $\psi(p, y)=\|p-y\|^{2}, \forall p, y \in H$. Furthermore, the following properties of $\psi$ can be verified easily from its definition:

(P1) $(\|p\|-\|q\|)^{2} \leq \psi(p, q) \leq(\|p\|+\|q\|)^{2}$

(P2) $\psi(p, q)=\psi(p, z)+\psi(z, q)+2\langle p-z, J z-J q\rangle$,

(P3) $\psi(p, q) \leq\|p\|\|J p-J q\|+\|q-p\|\|q\|$,

for all $p, q, z \in B$.

Definition 2.3 Let $B$ be a strictly convex, smooth and reflexive real Banach space and let $C$ be a nonempty, closed and convex subset of $B$. The map $\Pi_{C}: B \rightarrow C$ defined by $\tilde{t}:=\Pi_{C}(t)$ such that $\psi(\tilde{t}, t)=\inf _{y \in C} \psi(y, t)$ is called the generalized projection of $t$ onto $C$. Observe that in a real Hilbert space, the generalized projection $\Pi_{C}$ and the metric projection $P_{C}$ are equivalent.

Lemma 2.4 (Rockafellar, [36]) Let B be a smooth, strictly convex and reflexive real Banach space and $A: B \rightarrow 2^{B^{*}}$ be a monotone mapping. Then $A$ is maximal if and only if $R(J+r A)=$ $B^{*}, \forall r>0$.

Lemma 2.5 (Alber, [1]) Let C be a nonempty closed and convex subset of a smooth, strictly convex and reflexive real Banach space $B$. Then:

(1) given $t \in B$ and $y \in C, \tilde{t}=\Pi_{C} t$ if and only if $\langle\tilde{t}-y, J t-J \tilde{t}\rangle \geq 0$, for all $y \in C$,

(2) $\psi(y, \tilde{t})+\psi(\tilde{t}, t) \leq \psi(y, t)$, for all $t \in B, y \in C$.

Lemma 2.6 (Nilsrakoo and Saejung, [31]) Let B be a smooth Banach space. Then

$$
\psi\left(u, J^{-1}[\beta J t+(1-\beta) J y]\right) \leq \beta \psi(u, t)+(1-\beta) \psi(u, y), \quad \forall \beta \in[0,1], u, t, y \in B .
$$

Remark 1 Let $B$ be a smooth, strictly convex and reflexive real Banach space, let $C$ be a nonempty closed and convex subset of $B$ and let $A: B \rightarrow 2^{B^{*}}$ be a monotone operator satisfying

$$
D(A) \subset C \subset J^{-1}\left(\bigcap_{r>0} R(J+r A)\right) .
$$


Then we can define the resolvent $J_{r}: C \rightarrow D(A)$ of $A$ by

$$
J_{r} t=\{y \in D(A): J t \in(J y+r A y)\}, \quad \forall t \in C .
$$

It is well known that $J_{r} t$ is single-valued. For $r>0$, the Yosida approximation $A_{r}: C \rightarrow B^{*}$ is defined by $A_{r} t=\left(J t-J J_{r} t\right) / r$ for all $t \in C$.

Lemma 2.7 (Kohsaka and Takahashi, [22]) Let B be a smooth, strictly convex and reflexive real Banach space, let $C$ be a nonempty closed convex subset of $B$ and let $A: B \rightarrow 2^{B^{*}}$ be a monotone operator satisfying (2.2). Let $r>0$ and let $J_{r}$ and $A_{r}$ be the resolvent and the Yosida approximation of $A$, respectively. Then the following hold:

(i) $\psi\left(u, J_{r} t\right)+\psi\left(J_{r} t, t\right) \leq \psi(u, t), \forall t \in C, u \in A^{-1} 0$;

(ii) $\left(J_{r} t, A_{r} t\right) \in A, \forall t \in C$, where $\left(t, t^{*}\right) \in A$ denotes the value of $t^{*}$ at $t\left(t^{*} \in A t\right)$.

(iii) $F\left(J_{r}\right)=A^{-1} 0$.

Lemma $2.8(\mathrm{Xu},[47])$ Let $B$ be a uniformly convex Banach space and let $r>0$. Then there exists a strictly increasing, continuous, and convex function $g:[0, \infty) \rightarrow[0, \infty)$ such that $g(0)=0$ and

$$
\|\tau t+(1-\tau) y\|^{2} \leq \tau\|t\|^{2}+(1-\tau)\|y\|^{2}-\tau(1-\tau) g(\|t-y\|),
$$

for all $t, y \in B_{r}(0)$ and $\tau \in[0,1]$.

Lemma 2.9 (Kamimura and Takahashi, [20]) Let B be a uniformly convex and smooth real Banach space, and let $\left\{x_{n}\right\}$ and $\left\{y_{n}\right\}$ be two sequences of $B$. If either $\left\{x_{n}\right\}$ or $\left\{y_{n}\right\}$ is bounded and $\psi\left(x_{n}, y_{n}\right) \rightarrow 0$, then $\left\|x_{n}-y_{n}\right\| \rightarrow 0$.

Lemma 2.10 (Kohsaka and Takahash, [23]) Let C be a closed convex subset of a uniformly smooth and uniformly convex Banach space $B$ and let $\left(S_{i}\right)_{i=1}^{\infty}, S_{i}: C \rightarrow B$, for each $i \geq 1$, be a family of relatively nonexpansive maps such that $\bigcap_{i=1}^{\infty} F\left(S_{i}\right) \neq \emptyset$. Let $\left(\eta_{i}\right)_{i=1}^{\infty} \subset(0,1)$ and $\left(\mu_{i}\right)_{i=1}^{\infty} \subset(0,1)$ be sequences such that $\sum_{i=1}^{\infty} \eta_{i}=1$. Consider the map $T: C \rightarrow B$ defined by

$$
T t=J^{-1}\left(\sum_{i=1}^{\infty} \eta_{i}\left(\mu_{i} J t+\left(1-\mu_{i}\right) J S_{i} t\right)\right) \quad \text { for each } t \in C \text {. }
$$

Then $T$ is relatively nonexpansive and $F(T)=\bigcap_{i=1}^{\infty} F\left(S_{i}\right)$.

\section{Main result}

Theorem 3.1 Let $B$ be a uniformly convex and uniformly smooth real Banach space. Let $A$ : $B \rightarrow 2^{B^{*}}$ be a maximal monotone operator and let $J_{r}=(J+r A)^{-1} J$, for all $r>0$. Let $S: B \rightarrow B$ and $T: B \rightarrow B$ be relatively nonexpansive mappings such that $\Omega=F(S) \cap F(T) \cap A^{-1} 0 \neq \emptyset$. 
Define inductively the sequence $\left\{x_{n}\right\}$ by: $x_{0}, x_{1} \in B$

$$
\left\{\begin{array}{l}
C_{0}=B, \\
w_{n}=x_{n}+\alpha_{n}\left(x_{n}-x_{n-1}\right), \\
z_{n}=J^{-1}\left((1-\beta) J w_{n}+\beta J S J_{r_{n}} w_{n}\right), \\
u_{n}=J^{-1}\left((1-\gamma) J w_{n}+\gamma J T z_{n}\right), \\
C_{n+1}=\left\{z \in C_{n}: \psi\left(z, u_{n}\right) \leq \psi\left(z, w_{n}\right)\right\}, \\
x_{n+1}=\Pi_{C_{n+1}} x_{0},
\end{array}\right.
$$

for all $n \in \mathbb{N} \cup\{0\},\left\{\alpha_{n}\right\} \subset[0,1), \beta, \gamma \in(0,1)$ and $\left\{r_{n}\right\} \subset[a, \infty)$, for some $a>0$. Then $\left\{x_{n}\right\}$ converges strongly to $\Pi_{\Omega} x_{0}$.

Proof We divide the proof into four steps.

Step 1. We show that $\left\{x_{n}\right\}$ is well defined and $\Omega \subset C_{n}, \forall n \geq 0$. Observe that by definition, $C_{n+1}$ is closed and convex, $\forall n \geq 0$. We now show that $\Omega \subset C_{n}$. Let $y_{n}=J_{r_{n}} w_{n}$ and $u \in \Omega$. Using Lemma 2.6, the fact that $S$ is relatively nonexpansive and Lemma 2.7(i), we obtain

$$
\begin{aligned}
\psi\left(u, z_{n}\right) & =\psi\left(u, J^{-1}\left((1-\beta) J w_{n}+\beta J S y_{n}\right)\right) \\
& \leq(1-\beta) \psi\left(u, w_{n}\right)+\beta \psi\left(u, S y_{n}\right) \\
& \leq(1-\beta) \psi\left(u, w_{n}\right)+\beta \psi\left(u, y_{n}\right) \\
& =(1-\beta) \psi\left(u, w_{n}\right)+\beta \psi\left(u, J_{r_{n}} w_{n}\right) \\
& \leq(1-\beta) \psi\left(u, w_{n}\right)+\beta \psi\left(u, w_{n}\right) \\
& =\psi\left(u, w_{n}\right) .
\end{aligned}
$$

Similarly, using Lemma 2.6, the fact that $T$ is relatively nonexpansive and inequality (3.3), we have

$$
\begin{aligned}
\psi\left(u, u_{n}\right) & =\psi\left(u, J^{-1}\left((1-\gamma) J w_{n}+\gamma J T z_{n}\right)\right) \\
& \leq(1-\gamma) \psi\left(u, w_{n}\right)+\gamma \psi\left(u, T z_{n}\right) \\
& \leq(1-\gamma) \psi\left(u, w_{n}\right)+\gamma \psi\left(u, z_{n}\right) \\
& \leq(1-\gamma) \psi\left(u, w_{n}\right)+\gamma \psi\left(u, w_{n}\right)=\psi\left(u, w_{n}\right),
\end{aligned}
$$

which implies $u \in C_{n+1}$. So, by induction, $\Omega \subset C_{n}, \forall n \geq 0$. Thus, $\left\{x_{n}\right\}$ is well defined.

Step 2. We show that $\left\{x_{n}\right\},\left\{w_{n}\right\},\left\{z_{n}\right\},\left\{u_{n}\right\}$ are bounded and $\left\{x_{n}\right\}$ is Cauchy. We observe that $x_{n}=\Pi_{C_{n}} x_{0}$ and $C_{n+1} \subset C_{n}, \forall n \geq 0$. So, by Lemma 2.5(2)

$$
\psi\left(x_{n}, x_{0}\right) \leq \psi\left(x_{n+1}, x_{0}\right) .
$$

Thus, $\left\{\psi\left(x_{n}, x_{0}\right)\right\}$ is nondecreasing. Furthermore, we have

$$
\psi\left(x_{n}, x_{0}\right)=\psi\left(\Pi_{C_{n}} x_{0}, x_{0}\right) \leq \psi\left(u, x_{0}\right)-\psi\left(u, x_{n}\right) \leq \psi\left(u, x_{0}\right),
$$


which implies that $\left\{\psi\left(x_{n}, x_{0}\right)\right\}$ is bounded and by (P1), $\left\{x_{n}\right\}$ is also bounded. Since $\left\{\psi\left(x_{n}, x_{0}\right)\right\}$ is nondecreasing, $\left\{\psi\left(x_{n}, x_{0}\right)\right\}$ is convergent. Furthermore, $\left\{x_{n}\right\}$ bounded implies $\left\{w_{n}\right\}$ is bounded which also imply that $\left\{z_{n}\right\}$ and $\left\{u_{n}\right\}$ are bounded (by using inequalities (3.3) and (3.4), respectively and (P1)).

Next we show that $\left\{x_{n}\right\}$ is Cauchy. Using Lemma 2.5(2)

$$
\psi\left(x_{m}, x_{n}\right)=\psi\left(x_{m}, \Pi_{C_{n}} x_{0}\right) \leq \psi\left(x_{m}, x_{0}\right)-\psi\left(x_{n}, x_{0}\right) \rightarrow 0, \quad \text { as } n, m \rightarrow \infty .
$$

Hence, $\left\{x_{n}\right\}$ is Cauchy and this implies that $\left\|x_{n+1}-x_{n}\right\| \rightarrow 0$, as $n \rightarrow \infty$.

Step 3. We show the following:

- $\lim _{n \rightarrow \infty}\left\|x_{n}-w_{n}\right\|=0, \lim _{n \rightarrow \infty}\left\|x_{n}-u_{n}\right\|=0$,

- $\lim _{n \rightarrow \infty}\left\|z_{n}-T z_{n}\right\|=0, \lim _{n \rightarrow \infty}\left\|y_{n}-S y_{n}\right\|=0$.

Using the definition of $w_{n}$, we have

$$
\left\|x_{n}-w_{n}\right\|=\left\|\alpha_{n}\left(x_{n}-x_{n-1}\right)\right\| \leq\left\|x_{n}-x_{n-1}\right\| \rightarrow 0, \quad \text { as } n \rightarrow \infty .
$$

Now, using the fact that $\left\{w_{n}\right\}$ is bounded, we have $\psi\left(x_{n}, w_{n}\right) \rightarrow 0$, as $n \rightarrow \infty$. Since $x_{n+1} \in$ $C_{n}$, it follows that

$$
0 \leq \psi\left(x_{n+1}, u_{n}\right) \leq \psi\left(x_{n+1}, w_{n}\right) \rightarrow 0
$$

Thus, $\lim _{n \rightarrow \infty} \psi\left(x_{n+1}, u_{n}\right)=0$, which implies that $\lim _{n \rightarrow \infty}\left\|x_{n+1}-u_{n}\right\|=0$. Hence, $\lim _{n \rightarrow \infty}\left\|x_{n}-u_{n}\right\|=0$. By the uniform continuity of $J$ on bounded sets, we have

$$
\lim _{n \rightarrow \infty}\left\|J x_{n+1}-J x_{n}\right\|=\lim _{n \rightarrow \infty}\left\|J x_{n+1}-J u_{n}\right\|=\lim _{n \rightarrow \infty}\left\|J x_{n}-J u_{n}\right\|=0 .
$$

Observe that

$$
\begin{aligned}
\left\|J x_{n+1}-J u_{n}\right\| & =\left\|J x_{n+1}-(1-\gamma) J w_{n}-\gamma J T z_{n}\right\| \\
& =\left\|(1-\gamma)\left(J x_{n+1}-J w_{n}\right)+\gamma\left(J x_{n+1}-J T z_{n}\right)\right\| \\
& =\left\|\gamma\left(J x_{n+1}-J T z_{n}\right)-(1-\gamma)\left(J w_{n}-J x_{n+1}\right)\right\| \\
& \geq \gamma\left\|J x_{n+1}-J T z_{n}\right\|-(1-\gamma)\left\|J w_{n}-J x_{n+1}\right\|,
\end{aligned}
$$

which implies

$$
\left\|J x_{n+1}-J T z_{n}\right\| \leq \frac{1}{\gamma}\left(\left\|J x_{n+1}-J u_{n}\right\|+(1-\gamma)\left\|J w_{n}-J x_{n+1}\right\|\right) .
$$

Thus, $\lim _{n \rightarrow \infty}\left\|J x_{n+1}-J T z_{n}\right\|=0$. By the uniform continuity of $J^{-1}$ on bounded sets, we have $\lim _{n \rightarrow \infty}\left\|x_{n+1}-T z_{n}\right\|=0$. Furthermore,

$$
\left\|w_{n}-T z_{n}\right\| \leq\left\|w_{n}-x_{n+1}\right\|+\left\|x_{n+1}-T z_{n}\right\| \quad \Rightarrow \quad \lim _{n \rightarrow \infty}\left\|w_{n}-T z_{n}\right\|=0 .
$$


Next we show that $\lim _{n \rightarrow \infty}\left\|z_{n}-T z_{n}\right\|=\lim _{n \rightarrow \infty}\left\|y_{n}-S y_{n}\right\|=0$. Using Lemma 2.8 we have

$$
\begin{aligned}
\psi\left(u, z_{n}\right)= & \psi\left(u, J^{-1}\left((1-\beta) J w_{n}+\beta J S y_{n}\right)\right) \\
= & \|u\|^{2}-2\left\langle u,(1-\beta) J w_{n}+\beta J S y_{n}\right\rangle+\left\|(1-\beta) J w_{n}+\beta J S y_{n}\right\|^{2} \\
\leq & \|u\|^{2}-2\left\langle u,(1-\beta) J w_{n}\right\rangle-2\left\langle u, \beta J S y_{n}\right\rangle+(1-\beta)\left\|w_{n}\right\|^{2}+\beta\left\|S y_{n}\right\|^{2} \\
& -\beta(1-\beta) g\left(\left\|J w_{n}-J S y_{n}\right\|\right) \\
= & (1-\beta) \psi\left(u, w_{n}\right)+\beta \psi\left(u, S y_{n}\right)-\beta(1-\beta) g\left(\left\|J w_{n}-J S y_{n}\right\|\right) \\
\leq & \psi\left(u, w_{n}\right)-\beta(1-\beta) g\left(\left\|J w_{n}-J S y_{n}\right\|\right) .
\end{aligned}
$$

This implies that

$$
\beta(1-\beta) g\left(\left\|J w_{n}-J S y_{n}\right\|\right) \leq \psi\left(u, w_{n}\right)-\psi\left(u, z_{n}\right)
$$

Let $\left\{\left\|w_{n_{k}}-S y_{n_{k}}\right\|\right\}$ be an arbitrary subsequence of $\left\{\left\|w_{n}-S y_{n}\right\|\right\}$. Since $\left\{w_{n_{k}}\right\}$ is bounded, there exists a subsequence $\left\{w_{n_{k_{j}}}\right\}$ of $\left\{w_{n_{k}}\right\}$ such that

$$
\lim _{j \rightarrow \infty} \psi\left(u, w_{n_{k_{j}}}\right)=\limsup _{k \rightarrow \infty} \psi\left(u, w_{n_{k}}\right)=a
$$

Using (P2), (P3) and the fact that $T$ is relatively nonexpansive, we obtain

$$
\begin{aligned}
\psi\left(u, w_{n_{k_{j}}}\right)= & \psi\left(u, T z_{n_{k_{j}}}\right)+\psi\left(T z_{n_{k_{j}}}, w_{n_{k_{j}}}\right)+2\left\langle u-T z_{n_{k_{j}}}, J T z_{n_{k_{j}}}-J w_{n_{k_{j}}}\right\rangle \\
\leq & \psi\left(u, z_{n_{k_{j}}}\right)+\left\|T z_{n_{k_{j}}}\right\|\left\|J T z_{n_{k_{j}}}-J w_{n_{k_{j}}}\right\|+\left\|T z_{n_{k_{j}}}-w_{n_{k_{j}}}\right\|\left\|w_{n_{k_{j}}}\right\| \\
& +2\left\|u-T z_{n_{k_{j}}}\right\|\left\|J z_{n_{k_{j}}}-J w_{n_{k_{j}}}\right\| .
\end{aligned}
$$

Since $\lim _{n \rightarrow \infty}\left\|w_{n}-T z_{n}\right\|=0$ and hence $\lim _{n \rightarrow \infty}\left\|J x_{n}-J T z_{n}\right\|=0$ we obtain

$$
a=\lim _{j \rightarrow \infty} \psi\left(u, w_{n_{k_{j}}}\right) \leq \liminf _{j \rightarrow \infty} \psi\left(u, z_{n_{k_{j}}}\right) .
$$

We also have from inequality (3.3)

$$
\limsup _{j \rightarrow \infty} \psi\left(u, z_{n_{k_{j}}}\right) \leq \limsup _{j \rightarrow \infty} \psi\left(u, w_{n_{k_{j}}}\right)=a,
$$

and hence

$$
\lim _{j \rightarrow \infty} \psi\left(u, w_{n_{k_{j}}}\right)=\lim _{j \rightarrow \infty} \psi\left(u, z_{n_{k_{j}}}\right)=a .
$$

Thus, it follows from inequality (3.6) that $\lim _{j \rightarrow \infty} g\left(\left\|J w_{n_{k_{j}}}-J S y_{n_{k_{j}}}\right\|\right)=0$. By the properties of $g$, we have $\lim _{j \rightarrow \infty}\left\|J w_{n_{k_{j}}}-J S y_{n_{k_{j}}}\right\|=0$. By the uniform continuity of $J^{-1}$ on bounded sets, we obtain $\lim _{j \rightarrow \infty}\left\|w_{n_{k_{j}}}-S y_{n_{k_{j}}}\right\|=0$. Hence, $\lim _{n \rightarrow \infty}\left\|w_{n}-S y_{n}\right\|=0$. So, we have 
$\lim _{n \rightarrow \infty}\left\|J w_{n}-J S y_{n}\right\|=0$. Observe that

$$
\begin{aligned}
\left\|J z_{n}-J w_{n}\right\| & =\left\|(1-\beta) J w_{n}+\beta J S y_{n}-J w_{n}\right\| \\
& =\beta\left\|J S y_{n}-J w_{n}\right\| \\
& \leq\left\|J S y_{n}-J w_{n}\right\| .
\end{aligned}
$$

This implies that $\lim _{n \rightarrow \infty}\left\|J z_{n}-J w_{n}\right\|=0$, and hence $\lim _{n \rightarrow \infty}\left\|w_{n}-z_{n}\right\|=0$. Furthermore, from inequality (3.2), we have

$$
\frac{1}{\beta}\left(\psi\left(u, z_{n}\right)-(1-\beta) \psi\left(u, w_{n}\right)\right) \leq \psi\left(u, y_{n}\right)
$$

Using $y_{n}=J_{r_{n}} w_{n}$ and Lemma 2.7(i), we have

$$
\psi\left(y_{n}, w_{n}\right)=\psi\left(J_{r_{n}} w_{n}, w_{n}\right) \leq \psi\left(u, w_{n}\right)-\psi\left(u, J_{r_{n}} w_{n}\right)=\psi\left(u, w_{n}\right)-\psi\left(u, y_{n}\right)
$$

Thus, using inequality (3.8), we have

$$
\begin{aligned}
\psi\left(y_{n}, w_{n}\right) & \leq \psi\left(u, w_{n}\right)-\psi\left(u, y_{n}\right) \\
& \leq \psi\left(u, w_{n}\right)-\frac{1}{\beta}\left(\psi\left(u, z_{n}\right)-(1-\beta) \psi\left(u, w_{n}\right)\right) \\
& =\frac{1}{\beta}\left(\psi\left(u, w_{n}\right)-\psi\left(u, z_{n}\right)\right) \\
& =\frac{1}{\beta}\left(\left\|w_{n}\right\|^{2}-\left\|z_{n}\right\|^{2}-2\left\langle u, J w_{n}-J z_{n}\right\rangle\right) \\
& \leq \frac{1}{\beta}\left(\left|\left\|w_{n}\right\|-\left\|z_{n}\right\|\right|\left(\left\|w_{n}\right\|+\left\|z_{n}\right\|\right)+2\|u\|\left\|J w_{n}-J z_{n}\right\|\right) \\
& \leq \frac{1}{\beta}\left(\left\|w_{n}-z_{n}\right\|\left(\left\|w_{n}\right\|+\left\|z_{n}\right\|\right)+2\|u\|\left\|J w_{n}-J z_{n}\right\|\right) .
\end{aligned}
$$

This implies that $\lim _{n \rightarrow \infty} \psi\left(y_{n}, w_{n}\right)=0$. It follows from Lemma 2.9 that

$$
\lim _{n \rightarrow \infty}\left\|y_{n}-w_{n}\right\|=0
$$

Observe that

$$
\begin{aligned}
& \left\|z_{n}-T z_{n}\right\| \leq\left\|z_{n}-w_{n}\right\|+\left\|w_{n}-T z_{n}\right\| \quad \text { and } \\
& \left\|y_{n}-S y_{n}\right\| \leq\left\|y_{n}-w_{n}\right\|+\left\|w_{n}-S y_{n}\right\|,
\end{aligned}
$$

imply

$$
\lim _{n \rightarrow \infty}\left\|z_{n}-T z_{n}\right\|=\lim _{n \rightarrow \infty}\left\|y_{n}-S y_{n}\right\|=0
$$

Step 4. Finally, we show that $\left\{x_{n}\right\}$ converges strongly to a point in $\Omega$. Since $\left\{w_{n}\right\}$ is bounded, there exists a subsequence $\left\{w_{n_{k}}\right\}$ of $\left\{w_{n}\right\}$ such that $w_{n_{k}} \rightarrow p$. Furthermore, since $\lim _{n \rightarrow \infty}\left\|w_{n}-y_{n}\right\|=0$ and $\lim _{n \rightarrow \infty}\left\|w_{n}-z_{n}\right\|=0$, we have $y_{n_{k}} \rightarrow p$ and $z_{n_{k}} \rightarrow p$. Moreover, 
since $S$ and $T$ are relatively nonexpansive, we have $p \in \widehat{F}(S) \cap \widehat{F}(T)=F(S) \cap F(T)$. Next, we show that $p \in A^{-1} 0$. By the uniform continuity of $J$ on bounded sets, it follows from inequality (3.9) that

$$
\lim _{n \rightarrow \infty}\left\|J w_{n}-J y_{n}\right\|=0
$$

Since $r_{n} \geq a$, we have $\lim _{n \rightarrow \infty} \frac{1}{r_{n}}\left\|J w_{n}-J y_{n}\right\|=0$. Therefore,

$$
\lim _{n \rightarrow \infty}\left\|A_{r_{n}} w_{n}\right\|=\lim _{n \rightarrow \infty} \frac{1}{r_{n}}\left\|J x_{n}-J y_{n}\right\|=0
$$

Using the fact that $A$ is monotone and Lemma 2.7 (ii), we have

$$
\left\langle v-y_{n}, v^{*}-A_{r_{n}} w_{n}\right\rangle \geq 0, \quad \forall n \geq 0 .
$$

This implies that $\lim _{k \rightarrow \infty}\left\langle v-y_{n_{k}}, v^{*}-A_{r_{n_{k}}} w_{n_{k}}\right\rangle=\left\langle v-p, v^{*}\right\rangle \geq 0$. Thus, $p \in A^{-1} 0$, since $A$ is maximal monotone. Therefore, $p \in \Omega$. From Step 3, there exists $\left\{x_{n_{k}}\right\}$ a subsequence of $\left\{x_{n}\right\}$, such that $x_{n_{k}} \rightarrow p$, as $k \rightarrow \infty$. We now show that $p=\Pi_{\Omega} x_{0}$. Set $q=\Pi_{\Omega} x_{0}$. Using the fact that $x_{n}=\Pi_{C_{n}} x_{0}$ and $\Omega \subset C_{n}, \forall n \geq 0$, we have $\psi\left(x_{n}, x_{0}\right) \leq \psi\left(q, x_{0}\right)$. Using the fact that the norm is weakly lower semi-continuous, we obtain

$$
\begin{aligned}
\psi\left(p, x_{0}\right) & =\|p\|^{2}-2\left\langle p, J x_{0}\right\rangle+\left\|x_{0}\right\|^{2} \\
& \leq \liminf _{k \rightarrow \infty}\left(\left\|x_{n_{k}}\right\|^{2}-2\left\langle x_{n_{k}}, J x_{0}\right\rangle+\left\|x_{0}\right\|^{2}\right) \\
& \leq \liminf _{k \rightarrow \infty} \psi\left(x_{n_{k}}, x_{0}\right) \leq \limsup _{k \rightarrow \infty} \psi\left(x_{n_{k}}, x_{0}\right) \leq \psi\left(q, x_{0}\right) .
\end{aligned}
$$

But

$$
\psi\left(q, x_{0}\right) \leq \psi\left(z, x_{0}\right), \quad \forall z \in \Omega
$$

Thus, $\psi\left(p, x_{0}\right)=\psi\left(q, x_{0}\right)$. By uniqueness of $\Pi_{\Omega} x_{0}, p=q$. Next, we show that $x_{n_{k}} \rightarrow p$, as $k \rightarrow \infty$. Using inequalities (3.10) and (3.11), we obtain $\psi\left(x_{n_{k}}, x_{0}\right) \rightarrow \psi\left(p, x_{0}\right)$, as $k \rightarrow \infty$. Thus, $\left\|x_{n_{k}}\right\| \rightarrow\|p\|$, as $k \rightarrow \infty$. By the Kadec-Klee property of $B$, we conclude that $x_{n_{k}} \rightarrow p$ as $k \rightarrow \infty$. Therefore, $x_{n} \rightarrow \Pi_{\Omega} x_{0}$. This completes the proof.

Theorem 3.2 Let $B$ be a uniformly convex and uniformly smooth real Banach space. Let $A$ : $B \rightarrow 2^{B^{*}}$ be a maximal monotone operator and let $J_{r}=(J+r A)^{-1} J$, for all $r>0$. Let $T: B \rightarrow B$ be a relatively nonexpansive and let $\left\{S_{i}\right\}_{i=1}^{\infty}$ be a countable family of relatively nonexpansive maps such that $\bigcap_{i=1}^{\infty} F\left(S_{i}\right) \neq \emptyset$, where $S_{i}: B \rightarrow B, \forall i$. Let $\left\{\zeta_{i}\right\}_{i=1}^{\infty} \subset(0,1)$ and $\left\{\tau_{i}\right\}_{i=1}^{\infty} \subset(0,1)$ be sequences such that $\sum_{i=1}^{\infty} \zeta_{i}=1$. Assume $\Omega=\left(\bigcap_{i=1}^{\infty} F\left(S_{i}\right)\right) \cap F(T) \cap A^{-1} 0 \neq \emptyset$. Define in- 
ductively the sequence $\left\{x_{n}\right\}$ by: $x_{0}, x_{1} \in B$

$$
\left\{\begin{array}{l}
C_{0}=B, \\
w_{n}=x_{n}+\alpha_{n}\left(x_{n}-x_{n-1}\right), \\
z_{n}=J^{-1}\left((1-\beta) J w_{n}+\beta J S J_{r_{n}} w_{n}\right), \\
u_{n}=J^{-1}\left((1-\gamma) J w_{n}+\gamma J T z_{n}\right), \\
C_{n+1}=\left\{z \in C_{n}: \psi\left(z, u_{n}\right) \leq \psi\left(z, w_{n}\right)\right\}, \\
x_{n+1}=\Pi_{C_{n+1}} x_{0},
\end{array}\right.
$$

for all $n \in \mathbb{N} \cup\{0\}$, where $S t=J^{-1}\left(\sum_{i=1}^{\infty} \zeta_{i}\left(\tau_{i} J t+\left(1-\tau_{i}\right) J S_{i} t\right)\right)$ for each $t \in B,\left\{\alpha_{n}\right\} \subset[0,1)$, $\beta, \gamma \in(0,1)$ and $\left\{r_{n}\right\} \subset[a, \infty)$, for some $a>0$. Then $\left\{x_{n}\right\}$ converges strongly to $\Pi_{\Omega} x_{0}$.

Proof By Lemma 2.10, $S$ is relatively nonexpansive and $F(S)=\bigcap_{i=1}^{\infty} F\left(S_{i}\right)$. The conclusion follows from Theorem 3.1.

\section{Applications}

\subsection{Application to a convex optimization problem}

Let $X$ be a normed space and let $f: X \rightarrow(-\infty, \infty]$ be a convex, proper and lower semicontinuous function. The subdifferential of $f$ is defined by

$$
\partial f(t):=\left\{t^{*} \in X^{*}: f(y)-f(t) \geq\left\langle y-t, t^{*}\right\rangle, \forall y \in X\right\} .
$$

Observe that $0 \in \partial f(u)$ if and only if $u$ is a minimizer of $f$. Furthermore, it is well known that the subdifferential of $f, \partial f$ is maximal monotone (see, e.g., Rockafellar [37]). Set $A=\partial f$ in Theorem 3.2.

\subsection{Application to $J$-fixed point}

The notion of $J$-fixed point (which has also been called semi-fixed point, Zegeye [49], $d u$ ality fixed point, Liu [25]) has been defined and studied by Chidume and Idu [11], for maps from a space, say $X$, to its dual space $X^{*}$.

Definition 4.1 Let $T: X \rightarrow 2^{X^{*}}$ be any map. A point $u \in X$ is called a $J$-fixed point of $T$ if $J u \in T u$, where $J: X \rightarrow X^{*}$ is the single-valued normalized duality map on $X$.

Consider, for example, the evolution inclusion

$$
\frac{d u}{d t}+A u \ni 0
$$

where $A: B \rightarrow 2^{B^{*}}$ is monotone. At equilibrium, we have

$$
0 \in A u,
$$

and the solutions of Eq. (4.2) correspond to equilibrium states of (4.1). Define $T: B \rightarrow 2^{B^{*}}$ by $T:=J-A$. Then $u$ is a $J$-fixed point of $T$ if and only if $u$ is a solution of (4.2). Consequently, approximating solutions of (4.2) is equivalent to approximating $J$-fixed points 
of maps $T: X \rightarrow 2^{X^{*}}$ defined by $T:=J-A$. This connection is now generating considerable research interest in the study of $J$-fixed points (see, e.g., Chidume and Idu [11], Chidume and Monday [13], Chidume et al. $[15,16]$, and the references contained in them). This notion turns out to be very useful and applicable in approximating solutions of Eq. (4.2). For example, Chidume and Idu [11], introduced the concept of $J$ pseudocontractive maps and proved a strong convergence theorem for approximating $J$ fixed points of a $J$-pseudocontractive map. As an application of their theorem, they proved a strong convergence theorem for approximating a zero of a maximal monotone operator.

Recently, Chidume et al. [9] introduced the concept of relatively J-nonexpansive maps in a uniformly smooth and uniformly convex real Banach spaces. They gave the following definitions.

Definition 4.2 Let $T: B \rightarrow B^{*}$ be a map. A point $x^{*} \in B$ is called an asymptotic J-fixed point of $T$ if there exists a sequence $\left\{x_{n}\right\} \subset B$ such that $x_{n} \rightarrow x^{*}$ and $\left\|x_{n}-T x_{n}\right\| \rightarrow 0$, as $n \rightarrow \infty$. We shall denote the set of asymptotic $J$-fixed points of $T$ by $\widehat{F}_{J}(T)$.

Definition 4.3 A map $T: B \rightarrow B^{*}$ is said to be relatively J-nonexpansive if

(i) $\widehat{F}_{J}(T)=F_{J}(T) \neq \emptyset$,

(ii) $\psi\left(p, J^{-1} T x\right) \leq \psi(p, x), \forall x \in B, p \in F_{J}(T)$; where $F_{J}(T)=\{x \in B: T x=J x\}$.

Chidume et al. [9] used these new definitions in approximating a common $J$-fixed point of a countable family of relatively $J$-nonexpansive mappings in a uniformly convex and uniformly smooth real Banach space. We now use these definitions to prove a similar result. The following remark is key in the proof of the theorem below.

Remark 2 Observe that in the definition above, a mapping $T$ is relatively $J$-nonexpansive if and only if $J^{-1} T$ is relatively nonexpansive in the usual sense. Furthermore, $x^{*} \in F_{J}(T) \Leftrightarrow$ $x^{*} \in F\left(J^{-1} T\right)$.

Theorem 4.4 Let $B$ be a uniformly convex and uniformly smooth real Banach space. Let $A: B \rightarrow 2^{B^{*}}$ be a maximal monotone operator and let $J_{r}=(J+r A)^{-1} J$, for all $r>0$. Let $T: B \rightarrow B^{*}$ be a relatively nonexpansive and let $\left\{S_{i}\right\}_{i=1}^{\infty}$ be a countable family of relatively nonexpansive maps such that $\bigcap_{i=1}^{\infty} F\left(S_{i}\right) \neq \emptyset$, where $S_{i}: B \rightarrow B^{*}, \forall i$. Let $\left\{\zeta_{i}\right\}_{i=1}^{\infty} \subset(0,1)$ and $\left\{\tau_{i}\right\}_{i=1}^{\infty} \subset(0,1)$ be sequences such that $\sum_{i=1}^{\infty} \zeta_{i}=1$. Assume $\Omega=\left(\bigcap_{i=1}^{\infty} F\left(S_{i}\right)\right) \cap F(T) \cap$ $A^{-1} 0 \neq \emptyset$. Define inductively the sequence $\left\{x_{n}\right\}$ by: $x_{0}, x_{1} \in B$

$$
\left\{\begin{array}{l}
C_{0}=B, \\
w_{n}=x_{n}+\alpha_{n}\left(x_{n}-x_{n-1}\right), \\
z_{n}=J^{-1}\left((1-\beta) J w_{n}+\beta S J_{r_{n}} w_{n}\right), \\
u_{n}=J^{-1}\left((1-\gamma) J w_{n}+\gamma T z_{n}\right), \\
C_{n+1}=\left\{z \in C_{n}: \psi\left(z, u_{n}\right) \leq \psi\left(z, w_{n}\right)\right\}, \\
x_{n+1}=\Pi_{C_{n+1}} x_{0},
\end{array}\right.
$$

for all $n \in \mathbb{N} \cup\{0\}$, where $S x=J^{-1}\left(\sum_{i=1}^{\infty} \zeta_{i}\left(\tau_{i} J x+\left(1-\tau_{i}\right) J S_{i} x\right)\right)$ for each $t \in B,\left\{\alpha_{n}\right\} \subset[0,1)$, $\beta, \gamma \in(0,1)$ and $\left\{r_{n}\right\} \subset[a, \infty)$, for some $a>0$. Then $\left\{x_{n}\right\}$ converges strongly to $\Pi_{\Omega} x_{0}$. 
Proof By Remark 2, $J^{-1} T$ is relatively nonexpansive and $J^{-1} S_{i}$ is relatively nonexpansive for each $i$. The conclusion follows from Theorem 3.2.

\section{Numerical illustrations}

In this section, we give some examples to illustrate the effect of the inertial term in the fast convergence of the sequence of our algorithm. For simplicity, we consider an example in $\mathbb{R}$ and choose $A$ such that the resolvent can be easily computed.

Example 1 In Theorems 1.3 and 3.1 , set $B=C_{0}=\mathbb{R}$,

$$
A x=\frac{x}{3}, \quad T x=\sin x, \quad S x=\frac{1}{2}(x-\sin x) .
$$

Clearly, $A$ is maximal monotone and, $T$ and $S$ are relatively nonexpansive. Furthermore, $\Omega=\{0\}$. We choose $\alpha_{n}=\beta_{n}=\frac{4 n}{4 n+5}, r_{n}=\frac{2 n+1}{n}, \beta=\frac{1}{2}, \gamma=\frac{1}{4}$ as the parameters. Obviously, these parameters satisfy the hypothesis of Theorems 1.3 and 3.1. We choose $x_{0}=x_{1}=0.5$ and use a tolerance of $10^{-14}$ and set maximum number of iteration to be 2000 (see Tables 1 and 2 and Figs. 1 and 2).

Table 1 Table of values choosing $x_{0}=x_{1}=0.5$

\begin{tabular}{rlll}
\hline$n$ & Algorithm (1.5) & & Algorithm (3.1) \\
& $\left|x_{n+1}\right|$ & & $\left|x_{n+1}\right|$ \\
\hline 1 & 0.5 & 0.5 \\
3 & 0.2113 & 0.4167 \\
10 & 0.1717 & 0.0374 \\
16 & 0.1664 & 0.006 \\
30 & 0.1623 & $2.668 \times e^{-6}$ \\
60 & 0.1599 & $4.667 \times e^{-11}$ \\
85 & 0.1591 & $7.703 \times e^{-15}$ \\
100 & 0.1589 & Successful \\
200 & 0.1579 & Successful \\
500 & 0.1572 & Successful \\
1000 & 0.1568 & Successful \\
1500 & 0.1566 & Successful \\
2000 & 0.1565 & Successful \\
\hline
\end{tabular}

Table 2 Table of values choosing $x_{0}=-2, x_{1}=3$

\begin{tabular}{rlll}
\hline$n$ & Algorithm (1.5) & & Algorithm (3.1) \\
\cline { 2 - 2 } & $\left|x_{n+1}\right|$ & & $\left|x_{n+1}\right|$ \\
\hline 1 & 2 & 3 \\
3 & 0.8431 & 2 \\
10 & 0.6663 & 0.0532 \\
16 & 0.6365 & 0.0086 \\
30 & 0.6089 & $3.522 \times e^{-6}$ \\
60 & 0.5872 & $6.160 \times e^{-11}$ \\
85 & 0.5782 & $1.016 \times e^{-14}$ \\
100 & 0.5743 & Successful \\
200 & 0.5595 & Successful \\
500 & 0.5427 & Successful \\
1000 & 0.5313 & Successful \\
1500 & 0.5251 & Successful \\
2000 & 0.5207 & Successful \\
\hline
\end{tabular}




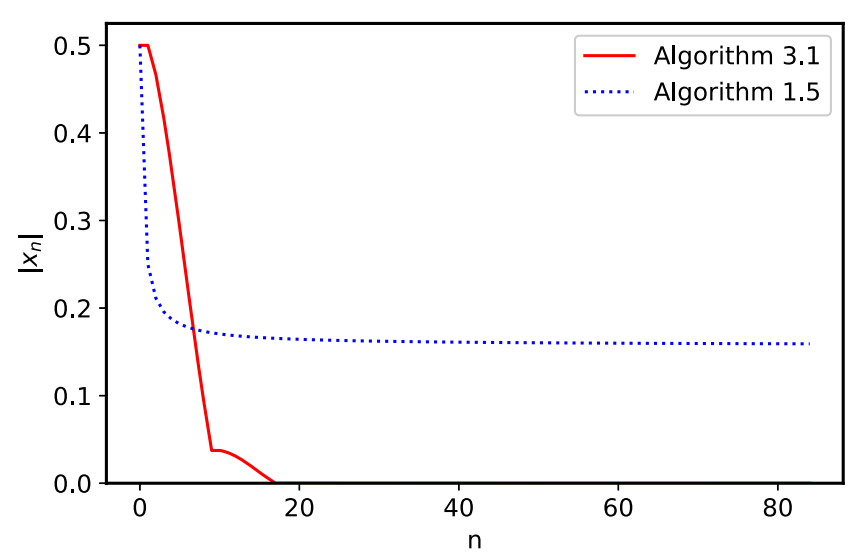

Figure 1 Graph of the first 85 iterates of Algorithms (1.5) and (3.1) choosing $x_{0}=x_{1}=0.5$

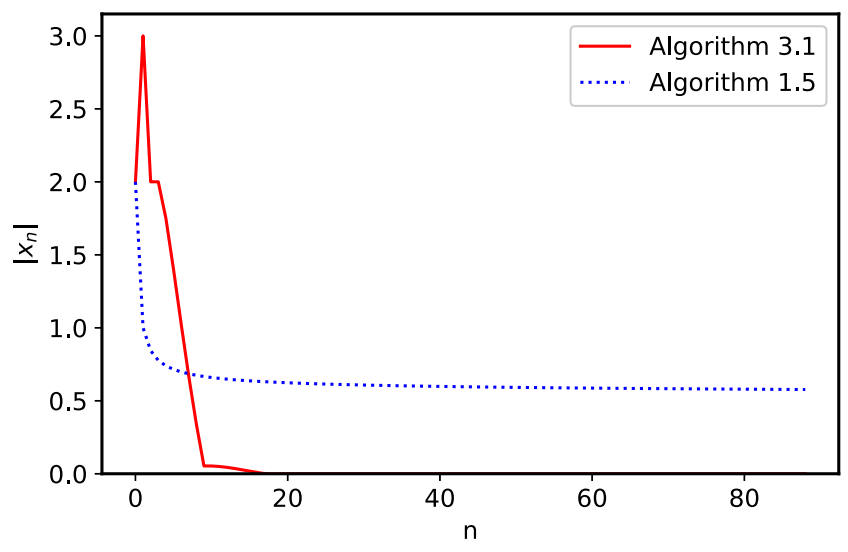

Figure 2 Graph of the first 85 iterates of Algorithms (1.5) and (3.1) choosing $x_{0}=-2, x_{1}=3$

Next, we give an example to show that Algorithm (3.12) is implementable.

Example 2 In Theorem 3.2, set $C_{0}=\mathbb{R}$

$$
A x=x, \quad T x=\frac{x}{3}, \quad S_{i} x=-\frac{\sin x}{2^{i}} .
$$

Clearly, $A$ is maximal monotone, $T$ is relatively nonexpansive and $S_{i}$ is relatively nonexpansive for each $i$. Furthermore, $\Omega=\left(\bigcap_{i=1}^{\infty} F\left(S_{i}\right)\right) \cap F(T) \cap A^{-1} 0=\{0\}$. We choose $\zeta_{i}=\tau_{i}=\frac{1}{2^{i}}$, $i \geq 1$, and $\alpha_{n}=\beta_{n}=\frac{4 n}{4 n+5}, r_{n}=\frac{2 n+1}{n}, \beta=\frac{1}{2}, \gamma=\frac{1}{4}$ as the parameters. Clearly, these parameters satisfy the hypothesis of Theorem 3.2. Observe that $S x=J^{-1}\left(\sum_{i=1}^{\infty} \eta_{i}\left(\mu_{i}\right) x+\right.$ $\left.\left.\left(1-\mu_{i}\right) S_{i} x\right)\right)=\frac{7 x-4 \sin x}{21}$. We choose $x_{0}=1, x_{1}=2.5$ and use a tolerance of $10^{-14}$ and set the maximum number of iterations to be 2000 (see Table 3 and Fig. 3).

Conclusion. From the numerical experiments above, we observe that indeed incorporating the inertial term in our algorithm speeds up the convergence of the sequence generated by our algorithm to the desired solution. 
Table 3 Table of values choosing $x_{0}=1, x_{1}=2.5$

\begin{tabular}{rl}
\hline$n$ & Algorithm (3.12) \\
\cline { 2 - 2 } & $\left|x_{n+1}\right|$ \\
\hline 1 & 2.5 \\
2 & 1 \\
3 & 0.0598 \\
4 & 0.0598 \\
5 & 0.0465 \\
10 & 0.0044 \\
20 & $1.425 \times e^{-5}$ \\
30 & $5.549 \times e^{-8}$ \\
40 & $8.18 \times e^{-11}$ \\
50 & $2.408 \times e^{-13}$ \\
55 & $3.521 \times e^{-15}$ \\
\hline
\end{tabular}

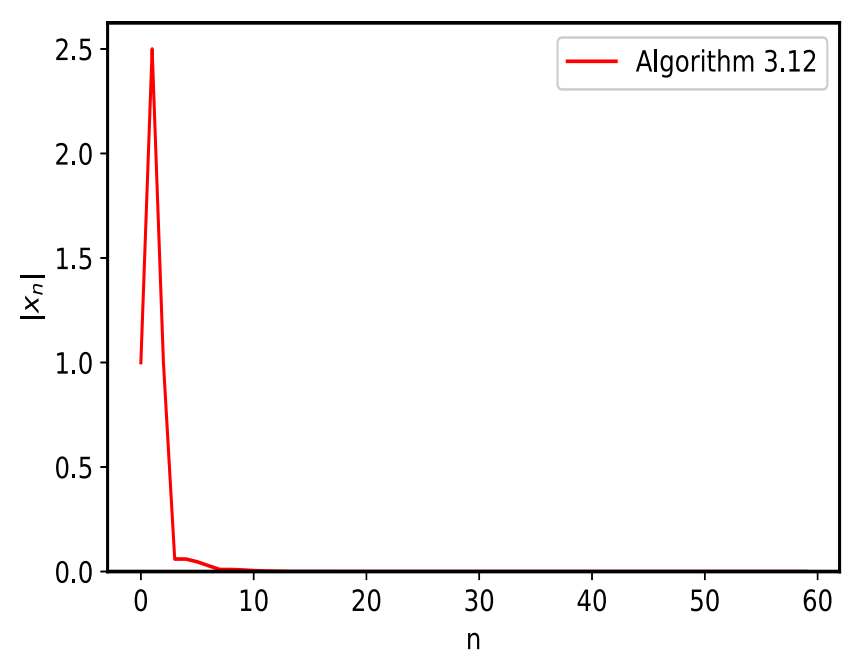

Figure 3 Graph of the first 55 iterates of Algorithm (3.12) choosing $x_{0}=1, x_{1}=2.5$

\section{Acknowledgements}

The authors acknowledge the African Development Bank (AfDB), the Pan African Material Institute (PAMI), AUST and the Center of Excellence in Theoretical and Computational Science (TaCS-CoE) for their financial support. The authors would like to thank the referees for their esteemed comments and suggestions.

\section{Funding}

This work is supported from the African Development Bank (AfDB) research grant funds to AUST and the Center of Excellence in Theoretical and Computational Science (TaCS-CoE) research grant to KMUTT.

\section{Availability of data and materials}

NA.

\section{Competing interests}

The authors declare that they have no conflict of interest.

\section{Authors' contributions}

CEC and PK formulated the problem and suggested the method of proof of the theorem to AA. The computations using the method suggested by CEC and PK was carried out by AA. The analysis of the computations to arrive at the proof of the Theorem was done jointly by CEC, PK and AA. All authors read and approved the final manuscript.

\section{Author details}

'African University of Science and Technology, Abuja, Nigeria. ${ }^{2}$ Center of Excellence in Theoretical and Computational Science (TaCS-CoE), Science Laboratory Building, King Mongkuts University of Technology Thonburi (KMUTT), Bangkok, Thailand. 


\section{Publisher's Note}

Springer Nature remains neutral with regard to jurisdictional claims in published maps and institutional affiliations.

\section{Received: 26 March 2020 Accepted: 1 July 2020 Published online: 01 August 2020}

\section{References}

1. Alber, Ya.l.: Metric and generalized projection operators in Banach spaces: properties and applications. In: Kartsatos, A.G. (ed.) Theory and Applications of Nonlinear Operators of Accretive and Monotone Type. Lecture Notes Pure Appl. Math., vol. 178, pp. 15-50 (1996)

2. Berinde, V: Iterative Approximation of Fixed Points. Lecture Notes in Mathematics. Springer, London (2007)

3. Browder, F.E.: Nonlinear elliptic boundary value problems. Bull. Am. Math. Soc. 69, 862-874 (1963)

4. Browder, F.E.: Existence and perturbation theorems for nonlinear maximal monotone operators in Banach spaces. Bull. Am. Math. Soc. 73(3), 322-327 (1967)

5. Chidume, C.E.: Geometric Properties of Banach Spaces and Nonlinear Iterations. Lectures Notes in Mathematics, vol. 1965. Springer, London (2009)

6. Chidume, C.E.: Strong convergence theorems for bounded accretive operators in uniformly smooth Banach spaces. Contemp. Math. 659, 31-41 (2016)

7. Chidume, C.E., Adamu, A., Chinwendu, L.O.: A Krasnoselskii-type algorithm for approximating solutions of variational inequality problems and convex feasibility problems. J. Nonlinear Var. Anal. 2(2), 203-218 (2018)

8. Chidume, C.E., Adamu, A., Chinwendu, L.O.: Iterative algorithms for solutions of Hammerstein equations in real Banach spaces. Fixed Point Theory Appl. (2020). https://doi.org/10.1186/s13663-020-0670-7

9. Chidume, C.E., Adamu, A., Chinwendu, L.O.: Strong convergence theorem for some nonexpansive-type mappings in certain Banach spaces. Thai J. Math. (in press)

10. Chidume, C.E., Chinwendu, L.O., Adamu, A.: A hybrid algorithm for approximating solutions of a variational inequality problem and a convex feasibility problem. Adv. Nonlinear Var. Inequal. 21(1), 46-64 (2018)

11. Chidume, C.E., Idu, K.O.: Approximation of zeros of bounded maximal monotone maps, solutions of Hammerstein integral equations and convex minimization problems. Fixed Point Theory Appl. (2016). https://doi.org/10.1186/s13663-016-0582-8

12. Chidume, C.E., Ikechukwu, S.I., Adamu, A.: Inertial algorithm for approximating a common fixed point for a countable family of relatively nonexpansive maps. Fixed Point Theory Appl. (2018). https://doi.org/10.1186/s13663-018-0634-3

13. Chidume, C.E., Nnakwe, M.O.: A new Halpern-type algorithm for a generalized mixedequilibrium problem and a countable family of generalizednonexpansive-type maps. Carpath. J. Math. 34(2), 191-198 (2018)

14. Chidume, C.E., Nnakwe, M.O., Adamu, A.: A strong convergence theorem for generalized- $\Phi$-strongly monotone maps, with applications. Fixed Point Theory Appl. (2019). https://doi.org/10.1186/s13663-019-0660-9

15. Chidume, C.E., Nnyaba, U.V., Romanus, O.M., Ezea, C.G.: Convergence theorems for strictly J-pseudocontractions with application to zeros of Gamma-inverse strongly monotone maps. Panam. Math. J. 26, 57-76 (2016)

16. Chidume, C.E., Uba, M.O., Uzochukwu, M.I., Otubo, E.E., Idu, K.O.: A strong convergence theorem for zeros of maximal monotone maps with applications to convex minimization and variational inequality problems. Proc. Edinb. Math. Soc. 62(1), 241-257 (2019)

17. Goebel, K., Reich, S.: Uniform Convexity, Hyperbolic Geometry, and Nonexpansive Mappings. Monographs and Textbooks in Pure and Applied Mathematics, vol. 83. Marcel Dekker, New York (1984)

18. Inoue, G., Takahashi, W., Zembayashi, K.: Strong convergence theorems by hybrid methods for maximal monotone operator and relatively nonexpansive mappings in Banach spaces. J. Convex Anal. 16(16), 791-806 (2009)

19. Kačurovskii, R.l: On monotone operators and convex functionals. Usp. Mat. Nauk 15(4), 213-215 (1960)

20. Kamimura, S., Takahashi, W.: Strong convergence of a proximal-type algorithm in a Banach space. SIAM J. Optim. 13, 938-945 (2002)

21. Klin-eam, C., Suantai, S., Takahashi, W.: Strong convergence of generalized projection algorithms for nonlinear operators. Abstr. Appl. Anal. 2009, Article ID 649831 (2009). https://doi.org/10.1155/2009/649831

22. Kohsaka, F., Takahashi, W.: Existence and approximation of fixed points of firmly nonexpansive-type mappings in Banach spaces. SIAM J. Optim. 19(2), 824-835 (2008)

23. Kohsaka, F., Takahashi, W.: The set of common fixed points of an infinite family of relatively nonexpansive mappings. In: Banach and Function Spaces II, pp. 361-373. Yokohama Publishers, Yokohama (2008)

24. Kumam, P., Wattanawitoon, K.: Convergence theorems of a hybrid algorithm for equilibrium problems. Nonlinear Anal. Hybrid Syst. 3, 386-394 (2009)

25. Liu, B.: Fixed point of strong duality pseudocontractive mappings and applications. Abstr. Appl. Anal. (2012). https://doi.org/10.1155/2012/623625

26. Maingé, P.E., Merabet, N.: A new inertial-type hybrid projection-proximal algorithm for monotone inclusions. Appl. Math. Comput. 215(9), 3149-3162 (2010)

27. Martin, R.H.: A global existence theorem for autonomous differential equations in Banach spaces. Proc. Am. Math. Soc. 26, 307-314 (1970)

28. Martinet, B.: Regularisation d'inequations variationelles par approximations successives. Rev. Fr. Inform. Rech. Oper. 4, 154-159 (1970)

29. Minty, G.J.: Monotone networks. Proc. R. Soc. Lond. 257, 194-212 (1960)

30. Minty, G.J.: Monotone (nonlinear) operators in Hilbert space. Duke Math. J. 29(4), 341-346 (1962)

31. Nilsrakoo, W., Saejung, S.: Strong convergence theorems by Halpern-Mann iterations for relatively nonexpansive maps in Banach spaces. Appl. Math. Comput. 217, 6577-6586 (2011)

32. Oteroa, R.G., lusem, A.N.: Proximal methods in reflexive Banach spaces without monotonicity. J. Math. Anal. Appl. 330(1), 433-450 (2007)

33. Petrot, N., Wattanawitoon, K., Kumam, P.: A hybrid projection method for generalized mixed equilibrium problems and fixed point problems in Banach spaces. Nonlinear Anal. Hybrid Syst. 4, 631-643 (2010)

34. Phuangphoo, P., Kumam, P.: Two block hybrid projection method for solving a common solution for a system of generalized equilibrium problems and fixed point problems for two countable families. Optim. Lett. (2013). https://doi.org/10.1007/s11590-012-0520-6 
35. Polyak, B.T.: Some methods of speeding up the convergence of iteration methods. USSR Comput. Math. Math. Phys. 4(5), 1-17 (1964)

36. Rockafellar, R.T: On the maximality of sums of nonlinear monotone operators. Trans. Am. Math. Soc. 149, 75-88 (1970)

37. Rockafellar, R.T.: Monotone operators and the proximal point algorithm. SIAM J. Control Optim. 14(5), 877-898 (1976)

38. Saewan, S., Cho, Y., Kumam, P.: Weak and strong convergence theorems for mixed equilibrium problems in Banach spaces. Optim. Lett. (2014). https://doi.org/10.1007/s11590-012-0593-2

39. Saewan, S., Kumam, P.: Convergence theorems for mixed equilibrium problems, variational inequality problem and uniformly quasi- $\psi$-asymptotically nonexpansive mappings. Appl. Math. Comput. 218, 3522-3538 (2011)

40. Saewan, S., Kumam, P.: A modified hybrid projection method for solving generalized mixed equilibrium problems and fixed point problems in Banach spaces. Comput. Math. Appl. 62, 1723-1735 (2011)

41. Saewan, S., Kumam, P.: A generalized $f$-projection method for countable families of weak relatively nonexpansive mappings and the system of generalized Ky Fan inequalities. J. Glob. Optim. (2013). https://doi.org/10.1007/s10898-012-9922-3

42. Saewan, S., Kumam, P., Kanjanasamranwonga, P.: The hybrid projection algorithm for finding the common fixed points of nonexpansive mappings and the zeroes of maximal monotone operators in Banach spaces. Optimization (2014) https://doi.org/10.1080/02331934.2012.724686

43. Takahashi, W., Zembayashi, K.: Strong and weak convergence theorems for equilibrium problems and relatively nonexpansive mappings in Banach spaces. Nonlinear Anal. 70, 45-57 (2009)

44. Thong, D.V., Hieu, D.V.: Inertial extragradient algorithms for strongly pseudomonotone variational inequalities. J. Comput. Appl. Math. 341(15), 80-98 (2018)

45. Wattanawitoon, K., Kumam, P.: Strong convergence theorems by a new hybrid projection algorithm for fixed point problems and equilibrium problems of two relatively quasi-nonexpansive mappings. Nonlinear Anal. Hybrid Syst. 3, $11-20$ (2009)

46. Wattanawitoon, K., Kumam, P.: The modified block iterative algorithms for asymptotically relatively nonexpansive mappings and the system of generalized mixed equilibrium problems. J. Appl. Math. 2012, Article ID 395760 (2012). https://doi.org/10.1155/2012/395760

47. Xu, H.K.: Inequalities in Banach spaces with applications. Nonlinear Anal. 16(12), 1127-1138 (1991)

48. Zarantonello, E.H.: Solving functional equations by contractive averaging. Technical report 160, U. S. Army Math. Research Center, Madison, WI (1960)

49. Zegeye, H.: Strong convergence theorems for maximal monotone maps in Banach spaces. J. Math. Anal. Appl. 343, 663-671 (2008)

\section{Submit your manuscript to a SpringerOpen ${ }^{0}$ journal and benefit from:}

- Convenient online submission

- Rigorous peer review

- Open access: articles freely available online

- High visibility within the field

Retaining the copyright to your article

Submit your next manuscript at $\boldsymbol{\nabla}$ springeropen.com 